\title{
ANALISIS PENGELOLAAN LABORATORIUM IPA DAN ALTERNATIF PRAKTIKUM IPA PADA MASA PANDEMI COVID-19 DI SMP NEGERI 1 CIAMIS
}

\author{
Eli Setiawati ${ }^{1}$, Taupik Sopyan², Adi Maladona ${ }^{3}$ \\ 1,2,3 Program Studi Pendidikan Biologi, Universitas Galuh, Jl. R. E. Martadinata No.150 , Ciamis, Indonesia \\ email: elisetiawati303@gmail.com
}

\begin{abstract}
The laboratory is one of the facilities in supporting practicum-based learning, especially in terms of management which needs to be considered. During the Covid-19 pandemic, SMPN 1 Ciamis has an alternative in carrying out practical activities that are interesting to know. The research method is descriptive qualitative. The research population is the principal, the head of the laboratory, the science teacher who is also the manager of the laboratory, and 8 students. The sampling technique used was the Snawball sampling. Research instruments in the form of interview guidelines, observation and documentation. The results of the study stated that the planning had been prepared with the needs of teachers and laboratory managers, the organization was not in accordance with the standards in Permendiknas No 26 of 2008 but was able to manage well, the implementation was in accordance with the plan and the needs of the IPA MGMP team, supervision was carried out formally and non-formally with pay attention to the substance of supervision then discussed in school meetings. Science teachers have independent practicum alternatives in the form of experiments and demonstrations using simple tools and materials that are easily found by students.
\end{abstract}

Keywords: Management, Science Laboratory, Alternative Practicum.

\begin{abstract}
ABSTRAK
Laboratorium merupakan salah satu sarana dalam menunjang pembelajaran berbasis praktikum terutama dari segi pengelolaan yang perlu diperhatikan. Pada masa pandemi Covid-19 ini SMPN 1 Ciamis memiliki alternatif dalam pelaksanan praktikum yang menarik untuk diketahui. Metode penelitian yaitu deskriptif kualitatif. Populasi penelitian adalah Kepala sekolah, Kepala Laboratorium, Guru IPA yang sekaligus pengelola Laboratorium, dan siswa 8 orang. Teknik pengambilan sampel menggunakan Snawball sampling. Instrumen penelitian berupa pedoman wawancara, observasi serta dokumentasi. Hasil penelitian menyatakan bahwa perencanaan telah disusun dengan kebutuhan guru dan pengelola laboratorium, pengorganisasian belum sesuai dengan standar pada permendiknas No 26 Tahun 2008 namun dapat mengelola dengan baik, pelaksanaan sesuai dengan yang direncanakan dan kebutuhan tim MGMP IPA, pengawasan dilakukan secara formal dan non formal dengan memperhatikan substansi supervisi kemudian dibahas dalam rapat sekolah. Guru IPA memiliki alternatif praktikum mandiri berupa eksperimen dan demonstrasi dengan menggunakan alat dan bahan sederhana yang mudah ditemui siswa.
\end{abstract}

Kata kunci: Pengelolaan, Laboratorium IPA, Alternatif Praktikum.

Cara Sitasi : Setiawati, E., Sopyan, T., \& Maladona, A. (2021). Analisis Pengelolaan Laboratorium IPA ddan Alternatif Praktikum IPA pada Masa Pandemi Covid-19 di Smp Negeri 1 Ciamis. J-KIP (Jurnal Keguruan dan IImu Pendidikan), 2(3), 229-236. 


\section{PENDAHULUAN}

Laboratorium merupakan salah satu fasilitas yang menunjang kelancaran kegiatan pembelajaran. Dengan adanya laboratorium, siswa dapat mengembangkan keterampilan teknis melalui peralatan yang ada di dalamnya. Siswa lebih mudah menemukan sumber belajar yang diinginkan. Keberadaan laboratorium sekolah (kegiatan praktikum) dapat menunjang kegiatan pembelajaran dan mencapai tiga bidang tujuan pendidikan, yaitu kognitif, afektif, dan psikomotorik (Yuliana et al., 2017).

Keberadaan dan kelangsungan laboratorium tergantung pada pengelolaannya. pengelolaan adalah kegiatan yang dimulai dengan perencanaan, pengorganisasian, pelaksanaan rencana kerja, pemantauan dan evaluasi rencana kerja. Pengelolaan laboratorium mempunyai pengaruh yang besar terhadap terwujudnya kegiatan praktikum sehingga dapat berjalan dengan baik dan efektif. (Zahara \& Agustina, 2018).

Fungsi utama dari pengelolaan menurut George R. Terry (dalam Nurdiansyah \& Rahman, 2019) memperkenalkannya dengan istilah POAC, yaitu:

\section{Perencanaan (Planning)}

Meliputi kegiatan merumuskan sasaran, penetapan strategi mencapai sasaran, menyusunan rencana untuk menyelaraskan dan mengoordinasi kegiatan.

2. Pengorganisasian (organization)

Merancang pekerjaan untuk mencapai sasaran organisasi melalui penyusunan struktur organisasi.

3. Pelaksanaan (Actuating)

Pengarahan dan motivasi seluruh pihak yang terlibat, sehingga mampu mengatasi atau menyelesaikan konflik.

4. Pengawasan/Pengendalian (controlling)

kegiatan pemantauan, evaluasi, dan melakukan perbaikan jika terdapat kegiatan yang menghambatan atau mengalami kegagalan dalam proses mencappai tujuan

Pengelolaan laboratorium telah diatur mengenai kualifikasi sarana dan prasarana laboratorium IPA dalam Peraturan Menteri Pendidikan Nasional (Permendiknas) No.24 tahun 2007, dan standar kompetensi pengelola laboratorium yang diatur dalam Peraturan Menteri Pendidikan Nasional (Permendiknas) No.26 tahun 2008.

Namun permasalahan dalam pengelolaan laboratorium IPA diungkapkan dalam penelitian di salah satu SMP di kabupaten Buleleng provinsi Bali oleh Turrahmah et al., (2020) yang menyimpulkan bahwa pengelolaaan laboratorium IPA dapat dikatakan belum baik karena masih banyak kegiatan pada program perencanaan belum dilaksanakan sesuai dengan apa yang sudah dibuat. Pengorganisasian yang meliputi struktur organisasi dan pengadministrasian belum dilaksanakan dengan baik seperti tidak adanya pembaharuan pada struktur organisasi di laboratorium. Pelaksanaan yang diantaranya kegiatan praktikum jarang dilakukan di ruang laboratorium dikarenakan keterbatasan alat dan bahan. Pengawasan dan evaluasi dilakukan dengan supervisi di intern sekolah dan adanya pengawas yang datang dari pemerintah.

Hasil observasi sementara laboratorium IPA di SMPN 1 Ciamis telah memiliki ruangan laboratorium fisika dan biologi yang representatif namun dari segi pengelolaan belum memiliki kualifikasi yang tepat terutama dari segi pengorganisasian. Selain itu pada masa pandemi covid-19, SMPN 1 Ciamis telah memiliki aternatif praktikum di masa pandemi berupa praktikum virtual. Untuk itu, peneliti tertarik untuk melakukan penelitian dengan rumusan masalah bagaimana perencanaan, pengorganisasian, pelaksanaan, pengawasan laboratorium IPA SMPN 1 Ciamis dan bagaimana alternatif praktikum IPA pada masa pandemi covid-19 di SMPN 1 Ciamis? 
Adapun tujuan dalam penelitian ini yaitu untuk mengetahui perencanaan, pengorganisasian, pelaksanaan, pengawasan laboratorium IPA SMPN 1 Ciamis. Dan untuk mengetahui alternatif praktikum IPA pada masa pandemi covid-19 di SMPN 1 Ciamis.

\section{METODE PENELITIAN}

Metode penelitian yaitu deskriptif kualitatif, menurut Sugiyono (2016) Metode penelitian kualitatif biasa disebut metode penelitian naturalistik karena penelitiannya dilakukan pada kondisi yang natural atau alamiah. Tujuannya adalah membuat deskripsi secara sistematis, faktual dan akurat tentang faktafakta dan sifat- sifat populasi atau obyek tertentu (Wahyu, 2021).

Teknik sampel dalam penelitian ini yaitu menggunakan teknik snowball sampling. Menurut Sugiyono (2016) snawball sampling merupakan teknik perolehan sampel sumber data, yang pada awalnya berjumlah sedikit, lama-lama menjadi banyak. Informan dalam penelitian ini yaitu kepala sekolah, kepala laboratorium, guru IPA, dan siswa. Prosedur pengumpulan data dilakukan melalui dua tahap yaitu tahap persiapan dan tahap pelaksanaan yang terdiri dari wawancara, observasi, dokumentasi dan triangulasi (penggabungan) sehingga hasil ataupun data dari penelitian akan dipaparkan sesuai dengan fakta yang terjadi.

\section{HASIL DAN PEMBAHASAN \\ Perencanaan Laboratorium IPA}

Program kerja yang dirancang dalam perencanaan laboratorium IPA di SMPN 1 Ciamis diantaranya program kegiatan laboratorium IPA, program tahunan laboratorium, dan jadwal penggunaan dan pemakaian laboratorium. Perencanaan pengadaan alat dan bahan di laboratorium IPA SMPN 1 Ciamis dilakukan melalui prosedur yang ditetapkan yaitu guru mengusulkan kebutuhan alat dan atau bahan laboratorium IPA kepada koordinator laboratorium Biologi atau Fisika, kemudian diajukan kepada kepala laboratorium untuk diinventarisir dan diajukan kepada bagian sarana dan prasarana. Pengajuan pelengkapan alat dan bahan laboratorium IPA disatukan dengan kebutuhan sekolah lainnya pada RKAS. Pengajuan pelengkapan alat dan bahan laboratorium IPA disatukan dengan kebutuhan sekolah lainnya pada RKAS. Perencanaan perumusan jadwal penggunaan laboratorium dilakukan dengan koordinasi antara guru IPA untuk mengantisipasi bentrok dalam pelaksanaanya

Perencanaan laboratorium dibuat supaya seluruh kegiatan laboratorium dapat terkelola dengan baik, tertib dan sumber daya laboratorium lebih optimal terutama dalam peningkatan mutu pembelajaran IPA. seperti yang diungkapkan oleh Terry (dalam Nurdiansyah \& Rahman, 2019) perencanaan meliputi kegiatan merumuskan sasaran, penetapan strategi mencapai sasaran, menyusunan rencana untuk menyelaraskan dan mengoordinasi kegiatan. Semua komponen penyusunan dilakukan oleh kepala laboratorium dan guru IPA agar semua perencanaan laboratorium dapat terorganisir dan disepakti oleh tim MGMP IPA.

Laboratorium IPA di SMPN 1 Ciamis sudah merencanakan secara matang hal-hal yang perlu dipersiapkan dalam mengelola laboratorium IPA. Sarana dan prasarana yang direncanakan merupakan bagian dari kepentingan penunjang pembelajaran IPA khususnya dalam pelaksanaan praktikum IPA. Analisis kebutuhan baik berupa alat dan bahan maupun sarana dan prasarana perlengkapan laboratorium IPA juga dilakukan oleh guru IPA yang mengacu pada kurikulum dan kebutuhan dalam menghadapi pembelajaran berupa praktikum, seperti yang diungkapkan oleh Nurhadi (2018) bahwa keefektifan suatu perencanaan sarana dan prasarana sekolah dapat di nilai atau dilihat dari seberapa jauh pengadaannya itu dapat memenuhi kebutuhan sarana dan prasarana sekolah dalam periode tertentu. Begitu juga dengan realisasi anggaran yang berasal dari dana BOS baik provinsi maupun pusat dan DAK (Dana Alokasi Khusus). 


\section{Pengorganisasian Laboratorum IPA}

Struktur organisasi laboratorium IPA di SMPN 1 Ciamis yaitu terdiri dari Kepala sekolah, Penanggung jawab program, kepala laboratorium IPA, koordinator laboratorium Biologi, koordinator laboratorium Fisika, Inventarisasi alat, dokumen Laporan dan kearsipan, dan Inventarisasi bahan. Dari struktur organisasi pengelola laboratorium IPA, kepala laboratorium berasal dari guru Penjaskesor, di SMPN 1 Ciamis kepala laboratorium menjadi kepala laboratorium dalam semua bidang, yaitu laboratorium bahasa, laboratorium Komputer dan laboratorium Matematika/IPS. Dengan struktur sebagai berikut:

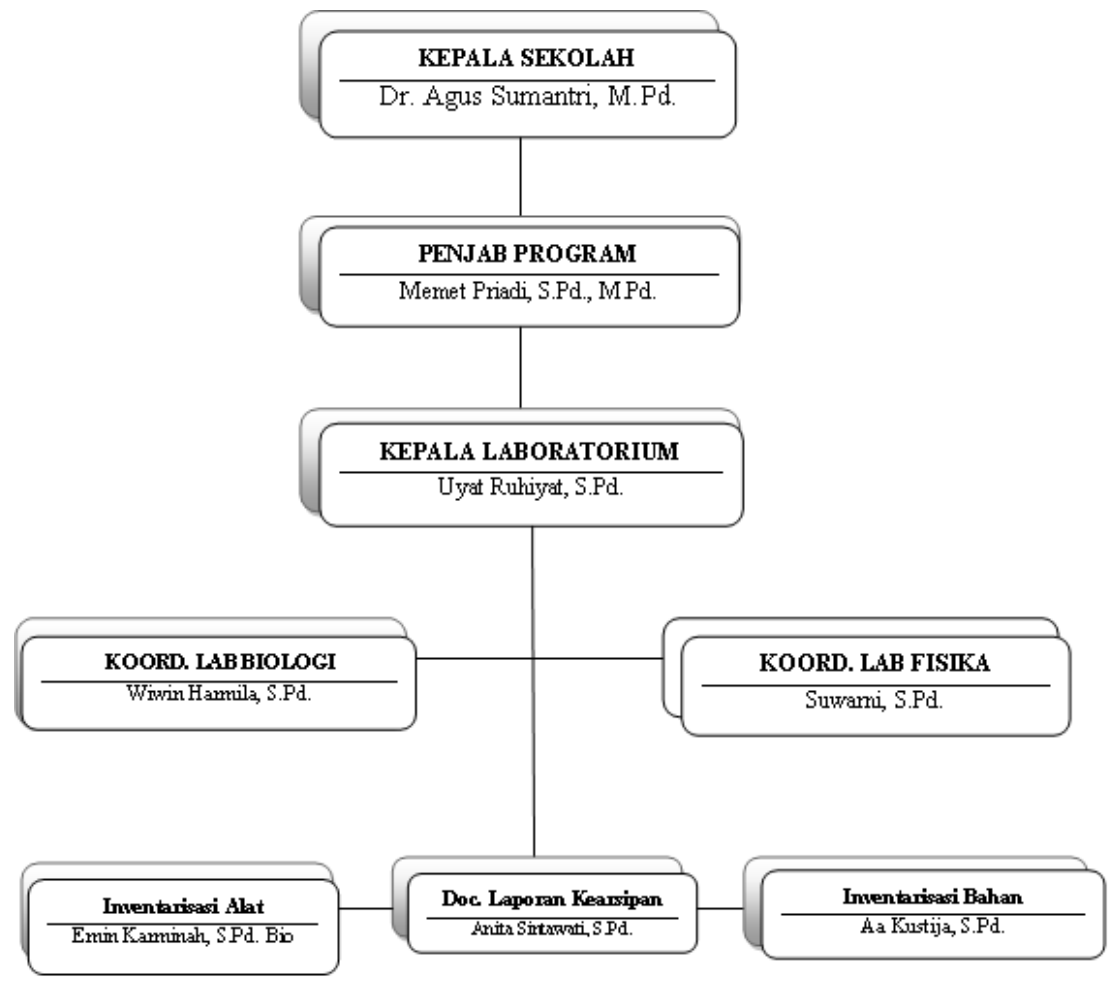

Semua guru IPA terlibat dalam pengelola laboratorium, dari semua pengelola laboratorium yang telah memiliki sertifikat pelatihan atau diklat yaitu hanya satu orang, guru IPA yang lain tidak memiliki sertifikat. Laboratorium IPA SMPN 1 Ciamis tidak memiliki laboran dan teknisi secara khusus, maka guru IPA berperan sebagai Laboran. Penetapan personil pengelola laboratorium IPA terutama kepala laboratorium ditunjuk oleh kepala sekolah, pengelola lainnya didiskusikan oleh kepala laboratorium dan tim MGMP IPA.

Kepala laboratorium IPA belum memiliki sertifikat diklat kepala laboratorium sebagai pelengkap kualifikasi dan bukan berasal dari guru mata pelajaran IPA, karena kepala labroatorium SMPN 1 Ciamis merupakan kepala laboratorium dalam semua bidang termasuk laboratorium IPS, TIK, dan yang lainnya. Sehingga dalam meningkatkan kualitas laboratorium tentunya tidak hanya fokus pada laboratorium IPA saja. Meski demikian, kepala laboratorium di SMPN 1 Ciamis dapat bertanggung jawab dalam memimpin jalannya pengelolalaan laboratorium IPA, hal tersebut dapat dilihat dari perlengkapan kebutuhan yang terpenuhi dan dukungan terhadap pengelola laboratorium yang merupakan guru IPA itu sendiri, karena semuan guru IPA terlibat menjadi pengelola laboratorium. 
Dalam permendiknas No. 26 Tahun 2008 telah diatur kualifikasi standar kepala laboratorium untuk tingkat sekolah/madrasah diatur yaitu :

1. Jalur Guru

a. Pendidikan minimal sarjana (S1);

b. Memiliki pengalaman menjadi pengelola laboratorium minimal 3 tahun;

c. Memiliki sertifikat kepala laboratorium dari perguruan tinggi maupun lembaga yang ditetapkan oleh pemerintah.

2. Jalur laboran/teknisi

a. Pendidikan minimal diploma tiga (D3);

b. Memiliki pengalaman menjadi laboran/teknisi minimal 5 tahun;

c. Memiliki sertifikat kepala laboratorium .

Secara struktural, kepala laboratorium IPA di SMPN 1 Ciamis perlu mengikuti kegiatan untuk memiliki sertifikat sebagai kualifikasi sebagai kepala laboratorium agar lebih kompeten dalam mengelola laboratorium.

\section{Pelaksanaan Laboratorium IPA}

Pelaksanaan laboratorium ini rangkaian pengelolaan laboratorium yang mengimplementasikan dari perencanaan yang telah disusun sedemikian rupa demi optimalnya pengelolaan laboratorium, seperti yang dikemukakan oleh Terry (dalam Nurdiansyah \& Rahman, 2019) bahwa pelaksaan ini merupakan pengarahan dan motivasi seluruh pihak yang terlibat, sehingga mampu mengatasi atau menyelesaikan konflik.

Dari segi pelaksanaanya jadwal penggunaan laboratorium IPA digunakan semua guru IPA baik yang mengajar di kelas 7, 8, dan kelas 9, pembagian jadwal penggunaan di laboratorium tidak ada bentrok dan dijadwalkan dengan kebutuhan pertahun, baik kebutuhan program kegiatan praktikum, maupun program kegiatan peningkatan sumber daya laboratorium. Program yang direncanakan dalam pelaksanakan pembelajaran di laboratorium disesuaikan dengan kompetensi dasar yang ada di RPP.

Pada pelaksanan praktikum di laboratorium Guru IPA menggunakan LKS yang digunakan sebagai petunjuk dan arahan untuk siswa dalam pelaksanaan praktikum, siswa mengetahui tata tertib di laboratorium yang diberitahu langsung oleh guru maupun membaca tata tertib yang berada di laboratorium dan mengaplikasikannya dalam proses pembelajaran. bentuk praktikum yang dilakukan yaitu berbasis eksperimen, observasi dan pembuatan proyek atau karya.

Kendala yang dihadapi oleh guru IPA atau pengelola laboratorium pada kegiatan praktikum yaitu sumber daya manusia karena guru harus mempersiapkan sendiri kebutuhan praktikum dikarenakan tidak adanya laboran khusus. Dalam pelaksanaan praktikum di laboratorium IPA SMPN 1 Ciamis, peran laboran digantikan oleh guru yang hendak melaksanakan praktikum dengan persiapan satu hari sebelum melaksanakan praktikum dengan cara menyetorkan alat dan bahan yang diperlukan dalam pelaksanan praktikum kepada koordinator laboratorium baik fisika maupun biologi. Kemudian pemeliharaan dilakukan setelah selesai melaksanakan praktikum yang dibantu oleh siswa baik dari kebersihan maupun kerapihan, alat dan bahan yang telah digunakan disimpan kembali ke tempat asalnya.

\section{Pengawasan/Supervisi Laboratorium IPA}

Pengawasan/Supervisi atau sering diistilahkan dengan kegiatan evaluasi berkaitan dengan kegiatan yang sedang maupun telah berjalan. Pada pengawasan di laboratorium IPA, Kepala sekolah menerima laporan dari kepala laboratorium terkait penggunaan laboratorium, kepala laboratorium beserta semua pengelola melakukan program untuk satu tahun, di akhir tahun ajaran wajib untuk 
dilaporkan pada kepala sekolah, substansi yang disupervisi yaitu berkaitan dengan program kegiatan laboratorium, inventarisasi alat dan bahan, daftar inventaris alat, jadwal penggunaan laboratorium, buku harian, buku permintaan dan peminjaman alat, kartu stok. Substansi tersebut wajib diketahui oleh kepala sekolah.

Kegiatan monitoring dan evaluasi secara formal di programkan dan dijadwalkan dari bagian kurikulum yaitu dalam satu tahun dilaksanakan dua kali, dalam pemantauannya dilakukan secara nonformal atau diluar jadwal yang sudah ditentukan oleh bagian kurikulum, pengawasan ini juga dilakukan untuk mencegah terjadinya ketidak sesuaian antara perencanaan yang telah disepakati yaitu dengan cara kepala sekolah setiap harinya keliling ke setiap kelas dan laboratorium untuk melakukan pengawasan pada pelaksanaan pembelajaran. Kegiatan pengawasan ini bertujuan untuk bahan evaluasi dan perbaikan untuk tahun selanjutnya. Sejalan dengan pengawasan menurut Zahara \& Agustina (2018) bahwa evaluasi program kerja dilakukan untuk masukan bagi pengambil keputusan mengenai program kerja yang telah disusun sehingga dapat dilakukan perbaikan maupun penyempurnaan program kerja ke depannya.

\section{Alternatif Praktikum IPA pada Masa Pandemi Covid-19}

Sebelum masa pandemi covid-19 siswa melaksanakan praktikum dengan menggunakan fasilitas yang sudah disediakan oleh sekolah terutama alat dan bahan yang akan digunakan dalam praktikum. Namun berbeda pada saat ini, guru harus lebih kreatif dalam pelaksanaan praktikum pada masa pandemi covid-19. Pada pelaksanaan praktikumnya, SMPN 1 Ciamis telah menggunakan berbagai inovasi agar praktikum bisa dilaksanakan yaitu dengan cara praktikum berbasis virtual menggunakan alat-alat sederhana yang mudah ditemukan di sekitar lingkungan siswa. praktikum yang telah digunakan pada masa pandemi covid-19 yaitu model demonstrasi dan eksperimen.

Pada model demonstrasi praktikum yang pernah dilakukan salah satunya mempelajari cermin cembung atau cekung diganti dengan alat yang berada dirumah oleh sendok, selain itu pada materi tekanan udara siswa melakukan demonstrasi menggunakan kertas hvs, gelas, dan air, pemanfaatan alat-alat sederhana tersebut membantu siswa dalam memahami materi yang sedang dipelajari. Selain itu kegiatan praktikum dalam bentuk eksperimen juga pernah dilakukan pada materi gerak fototropisme dengan menggunakan bahan yang mudah ditemui siswa yaitu kecambah kacang dan kapas, kemudian pengujian zat penyusun makhluk hidup dan benda mati pada kelas 9, kegiatan praktikum tersebut dilakukan sendiri dengan menggunakan alat yang mudah ditemui oleh siswa diantaranya korek api, lilin, piring kecil, bulu ayam, beberapa helai rambut manusia, kayu dan kertas.

Sebelum dilaksanakan praktikum virtual atau mandiri guru memberikan penjelasan berupa video, baik video yang dibuat oleh guru itu sendiri maupun video yang bersumber dari youtube untuk mempermudah siswa. Guru memberikan terlebih dahulu Lembar kerja siswa (LKS) melalui WhatsApp Grup kemudian dibahas dalam grup tersebut maupun melalui zoom meeting, dan langsung melaksanakan praktikum secara mandiri. Kegiatan praktikum yang dilaksanakan secara virtual atau mandiri terbatas alat dan bahan praktikum, tetapi kegiatan praktikum virtual membantu siswa untuk memahami dan menambah pengetahuan pada materi yang sedang dipelajari. Selama ini kegiatan praktikum berjalan dengan lancar, siswa mengumpulkan hasil praktikum berupa lembar kerja siswa (LKS) dan video dengan tepat waktu dan sesuai dengan prosedur dan arahan dari guru. Evaluasi terhadap pelaksanaan dilakukan oleh guru terhadap siswa, guru bisa memutar video berulang-ulang untuk mencari kekurangan dan kelebihan dari hasil praktikum. 


\section{KESIMPULAN}

Secara umum data yang diperoleh di SMPN 1 Ciamis dari segi pengelolaan laboratorium IPA mulai dari perencanaan, pengorganisasian, pelaksanan, dan pengawasan telah dilaksanakan dengan baik, namun dari segi pengorganisasian laboratorium IPA belum belum memiliki laboran khusus yang sesuai dengan permendiknas No 26 tahun 2008 tentang kualifikasi pengelola laboratorium, meski semua pengelola saling bekerja sama dan bertanggung jawab dan dapat berjalan dengan baik. Hal tersebut tetap saja harus diperhatikan untuk meningkatkan kualitas laboratorium.

Pada masa pandemi covid-19 ini pengelolaan laboratorium IPA tidak memiliki perubahan secara tertulis karena ruangan laboratorium IPA tidak dimaksimalkan, maka pihak sekolah terutama dari masing-masing personil pengelola laboratorium dan guru IPA tetap menekankan pada aspek pelaksanaan diaantaranya memiliki alternatif praktikum yang dilakukan secara daring dengan memanfaatkan alat dan bahan yang sederhana serta dengan media yang mudah dijangkau oleh siswa seperti WhatsApp, Zoom, maupun Google Classroom.

\section{REKOMENDASI}

Rekomendasi penelitian mengenai pengelolaan laboratorium dan alternatif praktikum IPA pada masa pandemi covid-19 ini diharapkan menjadi acuan kepada kepala sekolah agar lebih memberikan dukungan dan perhatian terkait pengelolaan laboratorium. Selain itu kepada pengelola laboratorium IPA dan tim MGMP IPA agar menjadi acuan terhadap pengoptimalan pengelolaan laboratorium dan terus memperhatikan sarana dan prasarana laboratorium, lebih menertibkan administrasi yang berkaitan dengan laboratorium, selain itu guru IPA dapat lebih kreatif dalam pelaksanaan praktikum berbasis virtual.

\section{UCAPAN TERIMAKASIH}

Penelitian ini tidak lepas dari dukungan dari berbagai pihak, oleh karena itu penulis mengucapkan terimakasih kepada Kepala sekolah SMPN 1 Ciamis, Pengelola Laboratorium IPA SMPN 1 Ciamis, tim MGMP IPA SMPN 1 Ciamis, dan Siswa SMPN 1 Ciamis yang telah memberikan informasi terkait penelitian.

\section{DAFTAR PUSTAKA}

Turrahmah, N., Pujani, N, M,. \& Selamet, K. (2020). Pengelolaan Laboratorium Ilmu Pengetahuan Alam (IPA) SMP Negeri 2 Singaraja. Jurnal Pendidikan dan Pembelajaran Sains. 3(2):118-129.

Nurdiansyah, H., \& Rahman, R. S. (2019). Pengantar Manajemen. Yogyakarta: Diandra Kreatif.

Nurhadi, A. (2018). Manajemen Laboratorium dalam Upaya Meningkatkan Mutu Pembelajaran. Tarbawi. $4(1): 1-12$.

Permendiknas RI No. 26 Tahun 2008. Standar Tenaga Laboratorium Sekolah/Madrasah. Jakarta: Depdiknas.

Sugiyono. (2016). Metode Penelitian Pendidikan Pendekatan kuantitatif, Kualitatif, dan R\&D. Bandung: Alfabeta. 
Yuliana., Hala, Y., \& Taiyeb, A. M..( 2017). Efektifitas Penggunaan Laboratorium Terhadap Motivasi dan Hasil Belajar IPA Peserta Didik SMPN 3 Paalakka Kabupaten Bone. Jurnal Nalar Pendidikan. 5(1):39-45.

Wahyu, F. S. (2021). Pemanfaatan instagram sebagai media alternatif ipa dalam masa pembelajaran jarak jauh (pjj). J-KIP (Jurnal Keguruan dan IImu Pendidikan), 2 (2), 81-90.

Zahara N., \& Agustina, E. 2018. Pemanfaatan dan Pengelolaan Laboratorium Bagi Guru IPA di Madrasah Tsanawiyah Negeri dan Swasta Aceh Besar. Prosiding Seminar Nasional Biotik: $750-755$. 